\title{
MicroRNA-26b inhibits tumor metastasis by targeting the KPNA2/c-jun pathway in human gastric cancer
}

\author{
Ming-Ming Tsai ${ }^{1,3, *}$, Hsiang-Wei Huang ${ }^{2, *}$, Chia-Siu Wang ${ }^{3, *}, K$ Kam-Fai Lee ${ }^{4}$, Chung- \\ Ying Tsai ${ }^{2}$, Pei-Hsuan Lu ${ }^{5}$, Hsiang-Cheng $\mathrm{Chi}^{2}$, Yang-Hsiang Lin ${ }^{2}$, Liang-Mou Kuo ${ }^{3}$, \\ Kwang-Huei Lin ${ }^{2,6}$ \\ ${ }^{1}$ Department of Nursing, Division of Basic Medical Sciences and Research Center for Industry of Human Ecology, Chang- \\ Gung University of Science and Technology, Taoyuan, 333, Taiwan \\ ${ }^{2}$ Department of Biochemistry, College of Medicine, Chang-Gung University, Taoyuan, 333, Taiwan \\ ${ }^{3}$ Department of General Surgery, Chang Gung Memorial Hospital at Chia-yi, Chia-yi, 613, Taiwan \\ ${ }^{4}$ Department of Pathology, Chang Gung Memorial Hospital, Chia-yi, 613, Taiwan \\ ${ }^{5}$ Department of Dermatology, Chang Gung Memorial Hospital, Chang Gung University, Taipei, 10508, Taiwan \\ ${ }^{6}$ Liver Research Center, Chang Gung Memorial Hospital, Linkou, Taoyuan, 333, Taiwan \\ *These authors contributed equally to this work
}

Correspondence to: Kwang-Huei Lin, email: khlin@mail.cgu.edu.tw

Keywords: miR-26b, KPNA2, c-jun, prognosis, gastric cancer

Received: July 17, 2015

Accepted: March 12, 2016

Published: April 07, 2016

\section{ABSTRACT}

MicroRnAs (miRNA) play an important role in carcinogenesis. Previously, we identified miR-26b as a significantly downregulated miRNA in gastric cancer (GC) tissues $(n=106)$ based on differential quantitative RT-PCR (RT-qPCR) miRNA expression profiles. In the current study, we aimed to clarify the potential role of miR-26b and related target genes in GC progression. Downregulation of miR-26b was associated with advanced tumor-node-metastasis stage (TNM stage) and poor 5-year survival rate. Forced expression of $\mathrm{miR}-26 \mathrm{~b}$ led to inhibition of GC cell migration and invasion in vitro and lung metastasis formation in vivo. Conversely, depletion of miR26b had stimulatory effects. Additionally, miR-26b affected GC cell behavior through negative regulation of the metastasis promoter, karyopherin alpha 2 (KPNA2). Ectopic expression of miR-26b induced a reduction in KPNA2 protein levels, confirmed by luciferase assay data showing that miR-26b directly binds to the 3' untranslated regions (UTR) of KPNA2 mRNA. Furthermore, miR-26b and KPNA2 mRNA/protein expression patterns were inversely correlated in GC tissues. Cag A of Helicobacter pylori $(H p)$ enhanced miR-26b levels through regulation of the KPNA2/c-jun pathway. Taken together, our data indicate that miR-26b plays an anti-metastatic role and is downregulated in GC tissues via the KPNA2/C-jun pathway. Based on the study findings, we propose that miR-26b overexpression or KPNA2/c-jun suppression may have therapeutic potential in inhibiting GC metastasis.

\section{INTRODUCTION}

Gastric cancer (GC) is one of the most common cancer types, and the second leading cause of cancerrelated mortality worldwide [1]. In 2014, GC was reported as the sixth leading cause of cancer mortality in Taiwan [2]. However, the molecular pathogenesis of the disease remains poorly understood. Patients with GC often show poor survival outcomes. The advanced clinical stage system is the only accepted method for predicting prognosis of clinical GC patients with progressive disease, with surgery being the only major therapeutic option. Identification of the pathogenic mechanisms involved in $\mathrm{GC}$ and development of useful prognostic biomarkers as well as novel targeted therapeutic strategies is therefore an urgent clinical necessity [3]. Recent studies have revealed the involvement of microRNAs (miRNAs) in the initiation and progression of several cancer types. MiRNAs are dysregulated in many cancers and function either as oncomiRs or tumor suppressors [4, 5]. In a previous study, 
we assessed differential RT-qPCR miRNA expression profiles and identified 30 differentially expressed miRNAs in GC tissues, compared with paired normal tissues [6]. Sixteen of these miRNAs were significantly downregulated $(<1.5$-fold, $p<0.05)$ and the remaining 14 significantly upregulated $(>1.5$-fold, $p<0.05)$ compared to paired normal tissues. Among these, miR-196a/-196b were identified as two of the most significantly upregulated miRNAs in GC tissues associated with promotion of tumor metastasis via downregulation of radixin, supporting their function as prometastatic oncomiRs [6]. Accumulating evidence has shown that miR-26b is downregulated in GC, implying a tumor suppressor role. Zhang et al. [7] reported that miR-26b inhibits adipogenic differentiation via suppressing HMGA1 in the ERK1/2 or JNK MAPK and adipogenesis pathways. Tan and colleagues identified a novel estrogen/MYC/miR-26 axis that mediates estrogen-stimulated breast cancer cell proliferation via CHD1, GREB1 and KPNA2 [8, 9]. In the current study, we sought to clarify the potential role and related target genes of miR-26b in GC progression and metastasis.

\section{RESULTS}

\section{MiR-26b is correlated with poor tumor progression}

In a previous study [6], differential RT-qPCR miRNA expression profile data revealed downregulation of miR-26b in GC tissues relative to paired normal tissues. To further confirm the decrease in miR-26b in GC, RT-qPCR was performed using 106 paired GC and normal tissues. The mean fold change in miR-26b expression in GC tissues was 1.364-fold (range, 0.028-15.589) greater, relative to that in paired normal tissues (Figure 1A). The means of $\mathrm{T}$ and $\mathrm{N}$ for miR-26b were -1.88 and -2.51 , respectively. We observed significant downregulation of miR-26b (1.46-fold) in GC tissues from 75/106 cases ( $p=0.0318$, Mann-Whitney $U$ test), consistent with miRNA profiling data (Figure 1B). Considering the definition of downregulation as $\mathrm{T} / \mathrm{N}$ ratio $<0.5$-fold, miR-26b was decreased in $67.92 \%$ GC tissues, relative to paired normal tissues. To establish the relationship between miR-26b expression and tumor progression, GC tissues were classified into four subgroups according to clinical stage. Patterns of miR-26b expression displayed a stepwise decrease upon GC progression from the early (I and II) to late (III and IV) stages ( $p<0.001$, MannWhitney $U$ test, Figure 1C). Our findings collectively indicate that low miR-26b expression is correlated with advanced tumor stage and lymph node metastasis.

\section{Clinicopathological correlations of miR-26b in GC tissues}

The relationships between miR-26b expression patterns and clinicopathological parameters of GC are summarized in Table 1. The characteristics of the study cases are listed $(n=106)$. Mean tumor size (maximum diameter) was $5.6 \mathrm{~cm}$ (median, $5.2 \mathrm{~cm}$; range, $0.3-20 \mathrm{~cm}$ ). Tumors were located in the proximal third of the stomach in $27(25.5 \%)$ cases, middle third in $24(22.6 \%)$ cases, distal third in $50(47.2 \%)$ patients, and the whole stomach in 5 $(4.7 \%)$ patients. Histological tumor types were intestinal $(n=36,34 \%)$ and diffuse $(n=70,66 \%)$. As defined by the depth of wall invasion, early GC (T1) was diagnosed in 26 (24.5\%), advanced GC (T2) (muscle proper and subserosa) in $13(12.3 \%)$, serosa (T3) in 51 (48.1\%), and invasion to adjacent organs (T4) in $16(15.1 \%)$ patients. Lymph node metastasis was diagnosed in 74 (69.8\%) patients. During surgery, liver metastasis was identified in three $(2.8 \%)$, peritoneal seeding in 20 (18.9\%), vascular invasion in $26(24.5 \%)$, lymphatic invasion in 61 $(57.5 \%)$, and perineural invasion in $38(35.8 \%)$ patients. In terms of pathological staging, $30(28.3 \%)$ patients were classified as stage I, $8(7.5 \%)$ as stage II, $38(35.8 \%)$ as stage III and 30 (28.3\%) as stage IV. Expression of miR$26 \mathrm{~b}$ in tumor tissues was not associated with age, gender and liver metastasis. Interestingly, miR-26b levels were closely correlated with location $(p=0.002)$, gross type $(p<0.001)$, histological type $(p=0.003)$, depth of invasion $(p<0.001)$, and serosal invasion $(p<0.001)$. MiR-26b was more significantly downregulated in T3 and T4 groups where the serosal surface of the gastric wall was invaded by cancer, compared to T1 and T2 groups where no invasion was evident ( $p=0.001)$, as well as in relation to higher lymph node status $(p<0.001)$, lymph node metastasis $(p<0.001)$, and distant metastasis $(p<0.001)$. Moreover, miR-26b was significantly decreased in patients displaying metastasis to the lymph nodes $(p<0.001)$ and those at more advanced pathologic stages (III and IV) of GC, compared to those in the earlier pathologic stages (I and II) $(p<0.001)$, as well as in patients with peritoneal seeding $(p<0.001)$, vascular invasion $(p<0.001)$, lymphatic invasion $(p<0.001)$ and perineural invasion $(p<0.001)$. Since miR-26b expression was negatively correlated with pathologic features (TNM stage), it is reasonable to hypothesize that loss of miR-26b expression promotes GC metastasis. The prognostic significance of miR-26b downregulation in GC was additionally determined via survival analysis. Univariate analysis with log-rank test disclosed parameters with significant prognostic influence on patient survival (Table 1). Figure 1D illustrates the cumulative survival curves of lower and higher expression groups of miR-26b using the median value $(=0.7)$ as the cut-off. Median follow-up duration for survivors $(n=53)$ was 83 months (range, 64-137 months). The five-year survival rate of the lower expression group was significantly higher than that of the higher expression group (78.5\% vs. 20.8\%, logrank $p<0.0001)$. Multivariate analysis (Cox regression) was performed to determine the independent prognostic potential of miR-26b for GC in relation to the significant clinicopathological parameters in univariate analysis. Histological type $(p=0.039$, hazards ratio $(\mathrm{HR})=2.263$, 
$95 \%$ confidence interval $(\mathrm{CI})=1.042-4.914)$ and miR-26b ( $p=0.045, \mathrm{HR}=2.473,95 \% \mathrm{CI}=1.02-5.996)$ emerged as significant independent prognostic biomarkers for GC in a stepwise forward-conditional multivariate regression model.

\section{MiR-26b inhibits GC cell invasion in vitro and metastasis in vivo}

Since clinicopathological data indicate that miR-26b is closely associated with GC metastasis, we postulated that miR-26b overexpression in GC cells should impede their invasive ability. To examine the association between miR-26b and invasiveness of GC cell lines, miR-26b-overexpressing and -depleted stable AGS and AZ-521 sublines were established. Images of miR-26boverexpressing and -depleted AGS and AZ-521 cell lines are depicted in Figure S1. Overexpression and suppression of miR-26b were confirmed using RT-qPCR (Figure S1). The effects of aberrant expression of miR-26b on cell migration and invasion activities were assayed using the Transwell method. Notably, miR-26b overexpressing AGS and AZ521 cells exhibited significantly lower migration rates (5.33and 5.08-fold, Figure S2A) and invasive abilities (3.61- and 4.55- fold, $p<0.001$, Mann-Whitney $U$ test, Figure 2A), compared to the respective control cell lines. Conversely,
miR-26b-depleted cells exhibited markedly higher migration (11.8- and 1.6-fold, $p<0.001$, Mann-Whitney $U$ test, Figure S2B) and invasion rates (2.73- and 2.06-fold, $p<0.001$, Mann-Whitney $U$ test, Figure 2C), relative to control cell lines. To further explore the role of miR-26b in tumor metastasis in vivo, SCID mice were transplanted with stable miR-26b-overexpressing or -depleted AGS cells through the lateral tail vein. Histological analysis of lungs of mice confirmed inhibition of lung metastasis nodules by miR-26b. In Figure 2B and 2D, the arrows indicate lung colonies. All lines of SCID mice also developed multiple macroscopic tumor nodules in lung, as observed with $\mathrm{H} \& \mathrm{E}$ staining. The average lung colony formation index was decreased 7.33-fold ( $p<0.01$, Mann-Whitney $U$ test, Figure 2B) in miR-26b-overexpressing cells and increased 9.08-fold ( $p<0.01$, Mann-Whitney $U$ test, Figure 2D) in miR-26b-depleted cells. Our data strongly indicate a metastasis suppressor role of miR-26b in GC.

\section{MiR-26b targets KPNA2 to suppress metastasis}

To explore the molecular mechanisms underlying the role of miR-26b in GC, TargetScan, a miRBase algorithm, was used and combined with differentially expressed proteins of the GC database from our laboratory isobaric tags for relative and absolute quantification (iTRAQ) (data

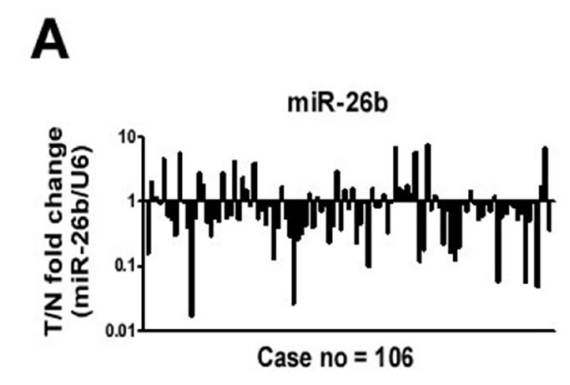

B
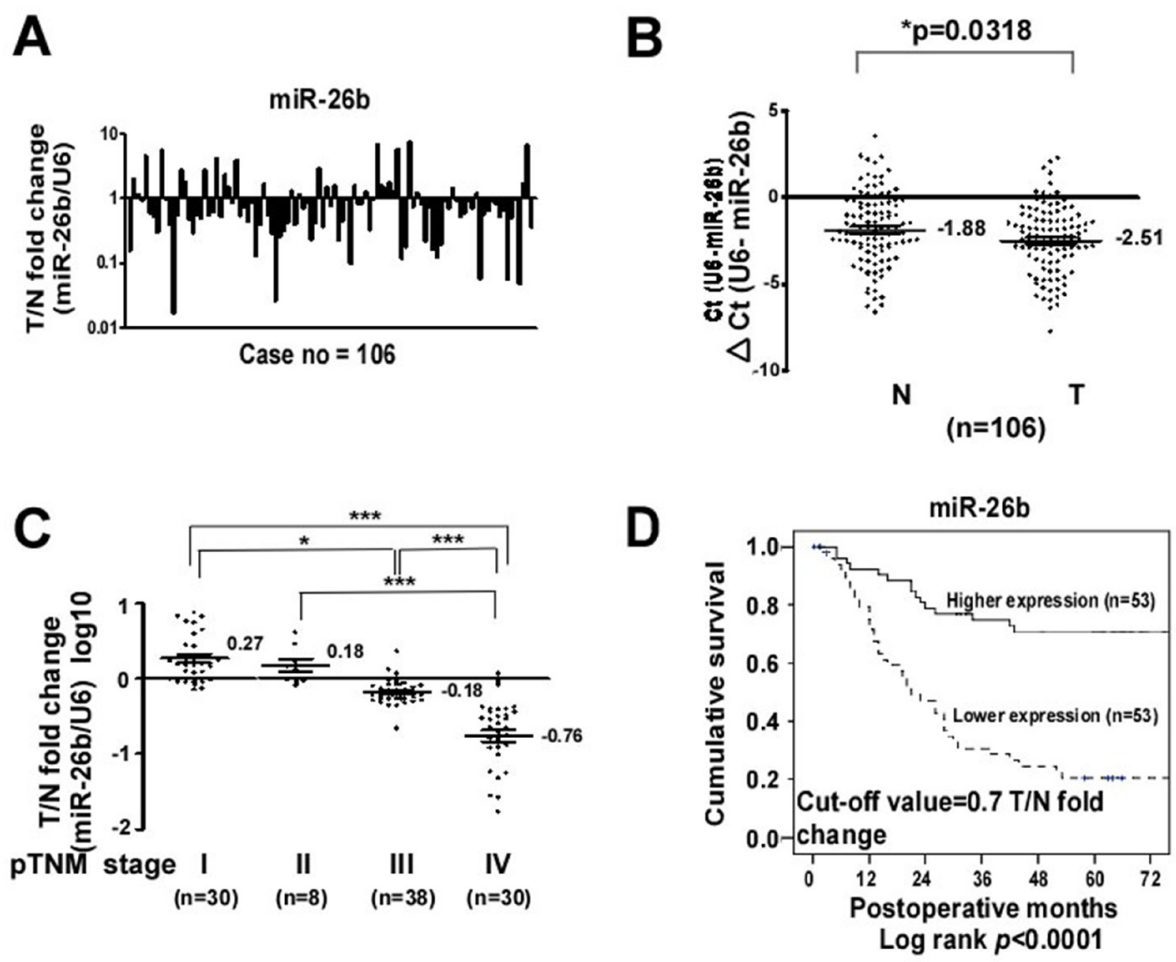

Figure 1: Downregulation of miR-26b in clinical GC tissues is correlated with advanced clinical stage and poor prognosis. (A) The miR-26b level was downregulated in $67.9 \%$ (72 of 106) of GC tumors (T), relative to paired normal tissues (N). (B) MiR-26b expression was determined using RT-qPCR and U6 normalization. (C) Expression levels of miR-26b at different clinical stages of GC. (D) MiR-26b expression vs five-year survival rate in $106 \mathrm{GC}$ tissues. Mann-Whitney $U$ test was used for comparison between the two groups. $* p<0.01, * * p<0.05, * * * p<0.001$. 
Table 1: Clinicopathological correlations of miR-26b expressions and 5-year survival rate in 106 GC patients

\begin{tabular}{|c|c|c|c|c|c|c|c|c|}
\hline \multicolumn{4}{|c|}{ Clinicopathological correlations } & \multicolumn{2}{|c|}{ Univariate analysis } & \multicolumn{3}{|c|}{ Multivariate analysis } \\
\hline Parameters & No. & Mean $\pm \mathrm{SE}^{\mathrm{a}}$ & $P^{\mathbf{b}}$ & 5-yr S.R. ${ }^{c}$ & Log $\operatorname{rank} P^{d}$ & HR & $95 \% \mathrm{CI}$ & $\boldsymbol{P}^{f}$ \\
\hline \multicolumn{9}{|l|}{ Age (yrs) } \\
\hline$<65$ & 56 & $1.07 \pm 0.19$ & 0.418 & 41.5 & 0.2706 & & & \\
\hline$\geq 65$ & 50 & $1.24 \pm 0.21$ & & 51.9 & & & & \\
\hline \multicolumn{9}{|l|}{ Gender } \\
\hline Male & 59 & $1.18 \pm 0.20$ & 0.474 & 41.7 & 0.3521 & & & \\
\hline Female & 47 & $1.12 \pm 0.19$ & & 52.2 & & & & \\
\hline \multicolumn{9}{|l|}{ Location } \\
\hline Upper third & 27 & $1.53 \pm 0.38$ & 0.002 & 56.0 & 0.0025 & & & \\
\hline Middle third & 24 & $1.55 \pm 0.24$ & & 49.1 & & & & \\
\hline Lower third & 50 & $0.83 \pm 0.17$ & & 44.3 & & & & \\
\hline Whole & 5 & $0.48 \pm 0.17$ & & 0.0 & & & & \\
\hline Gross type & & & & & & 1.157 & $0.51-2.626$ & 0.727 \\
\hline Localized & 44 & $1.89 \pm 0.29$ & $<0.001$ & 74.2 & $<0.0001$ & & & \\
\hline Infiltrative & 62 & $0.63 \pm 0.08$ & & 25.4 & & & & \\
\hline Histological type & & & & & & 2.263 & $1.042-4.914$ & 0.039 \\
\hline Intestinal & 36 & $1.81 \pm 0.35$ & 0.003 & 71.3 & $<0.0001$ & & & \\
\hline Diffuse & 70 & $0.81 \pm 0.10$ & & 32.3 & & & & \\
\hline $\begin{array}{l}\text { Depth of invasion } \\
\text { (pT) }\end{array}$ & & & & & & 0.758 & $0.244-2.355$ & 0.632 \\
\hline $\mathrm{T} 1$ & 26 & $2.30 \pm 0.38$ & $<0.001$ & 91.8 & $<0.0001$ & & & \\
\hline $\mathrm{T} 2$ & 13 & $1.96 \pm 0.56$ & & 59.8 & & & & \\
\hline $\mathrm{T} 3$ & 51 & $0.63 \pm 0.06$ & & 29.2 & & & & \\
\hline $\mathrm{T} 4$ & 16 & $0.30 \pm 0.07$ & & 13.3 & & & & \\
\hline Serosal invasion & & & & & & 2.135 & $0.818-5.571$ & 0.121 \\
\hline No $(\mathrm{T} 1, \mathrm{~T} 2)$ & 39 & $2.18 \pm 0.31$ & $<0.001$ & 81.0 & $<0.0001$ & & & \\
\hline Yes $(\mathrm{T} 3, \mathrm{~T} 4)$ & 67 & $0.56 \pm 0.05$ & & 25.4 & & & & \\
\hline $\begin{array}{l}\text { Lymph node } \\
\text { status (pN) }\end{array}$ & & & & & & 1.608 & $0.328-7.878$ & 0.558 \\
\hline N0 & 32 & $2.15 \pm 0.36$ & $<0.001$ & 86.7 & $<0.0001$ & & & \\
\hline N1 & 33 & $1.07 \pm 0.18$ & & 43.3 & & & & \\
\hline N2 & 19 & $0.51 \pm 0.07$ & & 28.5 & & & & \\
\hline N3 & 22 & $0.37 \pm 0.10$ & & 4.8 & & & & \\
\hline \multicolumn{9}{|l|}{$\begin{array}{l}\text { Lymph node } \\
\text { metastasis }\end{array}$} \\
\hline No (N0) & 32 & $2.15 \pm 0.36$ & $<0.001$ & 86.7 & $<0.0001$ & & & \\
\hline Yes (N1, N2, N3) & 74 & $0.72 \pm 0.09$ & & 28.2 & & & & \\
\hline $\begin{array}{l}\text { Distant metastasis } \\
\text { (pM) }\end{array}$ & & & & & & & & \\
\hline
\end{tabular}




\begin{tabular}{|c|c|c|c|c|c|c|c|c|}
\hline No & 79 & $1.46 \pm 0.18$ & $<0.001$ & 60.1 & $<0.0001$ & & & \\
\hline Yes & 27 & $0.24 \pm 0.04$ & & 4.0 & & & & \\
\hline $\begin{array}{l}\text { Pathological stage } \\
\text { (pStage) }\end{array}$ & & & & & & 7.771 & $0.971-62.201$ & 0.053 \\
\hline I & 30 & $2.45 \pm 0.37$ & $<0.001$ & 92.9 & $<0.0001$ & & & \\
\hline II & 8 & $1.76 \pm 0.41$ & & 75.0 & & & & \\
\hline III & 38 & $0.71 \pm 0.06$ & & 36.1 & & & & \\
\hline IV & 30 & $0.25 \pm 0.04$ & & 3.6 & & & & \\
\hline \multicolumn{9}{|l|}{ Pathological stage } \\
\hline Stages I, II & 38 & $2.30 \pm 0.31$ & $<0.001$ & 88.9 & $<0.0001$ & & & \\
\hline Stages III, IV & 68 & $0.51 \pm 0.04$ & & 21.9 & & & & \\
\hline \multicolumn{9}{|l|}{ Liver metastasis } \\
\hline No & 103 & $1.18 \pm 0.14$ & 0.063 & 47.7 & 0.1102 & & & \\
\hline Yes & 3 & $0.30 \pm 0.08$ & & 0.0 & & & & \\
\hline $\begin{array}{l}\text { Peritoneal } \\
\text { seeding }\end{array}$ & & & & & & 1.469 & $0.552-3.914$ & 0.441 \\
\hline No & 86 & $1.36 \pm 0.17$ & $<0.001$ & 56.2 & $<0.0001$ & & & \\
\hline Yes & 20 & $0.26 \pm 0.05$ & & 0.0 & & & & \\
\hline Vascular invasion & & & & & & 1.667 & $0.893-3.111$ & 0.108 \\
\hline No & 80 & $1.40 \pm 0.18$ & $<0.001$ & 57.4 & $<0.0001$ & & & \\
\hline Yes & 26 & $0.39 \pm 0.07$ & & 8.7 & & & & \\
\hline $\begin{array}{l}\text { Lymphatic } \\
\text { invasion }\end{array}$ & & & & & & 1.917 & $0.704-5.218$ & 0.203 \\
\hline No & 45 & $2.03 \pm 0.28$ & $<0.001$ & 79.2 & $<0.0001$ & & & \\
\hline Yes & 61 & $0.50 \pm 0.05$ & & 21.1 & & & & \\
\hline $\begin{array}{l}\text { Perineural } \\
\text { invasion }\end{array}$ & & & & & & 1.008 & $0.541-1.877$ & 0.98 \\
\hline No & 68 & $1.49 \pm 0.20$ & $<0.001$ & 59.5 & $<0.0001$ & & & \\
\hline Yes & 38 & $0.54 \pm 0.08$ & & 22.2 & & & & \\
\hline $\begin{array}{l}\text { miR-26b } \\
\text { (qRT-PCR) }\end{array}$ & & & & & & 2.473 & $1.02-5.996$ & 0.045 \\
\hline$<0.7{\text { (medium })^{\mathrm{e}}}^{\mathrm{e}}$ & 53 & $1.15 \pm 0.14$ & & 20.4 & $<0.0001$ & & & \\
\hline$\geq 0.7$ & 53 & & & 70.9 & & & & \\
\hline
\end{tabular}

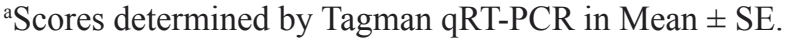

${ }^{b}$ Mann-Whitney $U$ test (for 2 groups) or Kruskal-Wallis test (for $>2$ groups).

${ }^{c}$ Five-year survival rate.

${ }^{\mathrm{d}}$ Log rank test.

e50th percentile.

${ }^{f}$ Hazard ratios, $95 \% \mathrm{CI}$ and $P$ values were generated using a Cox proportional hazard analysis.

not shown) to identify the putative protein coding gene targets of miR-26b, particularly those with oncogenic functions (Figure S3A). Consequently, 11 candidate genes (CSTF2, KPNA2, LRPPRC, DRG1, LYN, SFPQ, ALDH5A1, GMFB, SLC12A2, AGPAT5 and DIDO1) were selected (Supplementary Table S1A). Reporter assays were performed with each $3{ }^{\prime} \mathrm{UTR}$ to screen for genes with activities repressed by miR-26b. The 3'UTR regions of the 11 potential candidate gene sequences were amplified and cloned into pMIR-REPORT Luciferase 
vector (Supplementary Table S1B). Among these, KPNA2 activity was significantly altered by miR-26b (Figure S3B and S3C). To further ascertain whether KPNA2 is a direct target of miR-26b, the 3'UTR and its corresponding mutant counterparts were fused to the pMIR-REPORT Luciferase vector. Notably, reporter activities of wild-type $3^{\prime}$ UTR, but not mutant 3'UTR, were suppressed by miR-26b. This regulation was dependent on specific sequences, as shown in Figure 3A (left). The results collectively indicate that miR-26b downregulates KPNA2 expression by directly targeting its 3'UTR. In addition, western blot analysis revealed that the KPNA2 level is decreased by $0.71-$ and 0.65-fold in AGS and AZ-521 cells overexpressing miR$26 \mathrm{~b}$, respectively (Figure $3 \mathrm{~B}$ ). Conversely, the KPNA2 level was increased 1.57- and 2.63-fold in AGS and AZ521 cells depleted of miR-26b, respectively (Figure 3C), confirming regulation of KPNA2 expression by miR-26b in GC. Expression levels of KPNA2 in 67 paired cases were examined to establish its potential clinicopathological associations (Figure 3D). KPNA2 expression was higher in $76.1 \%$ of tumor samples, compared to their normal tissue counterparts. KPNA2 protein levels were additionally evaluated in 77 paired cases via IHC (Figure 3E). Mean IHC scores of tumor versus paired normal tissues were 53.38 and 5.06, respectively, with significant differences $(p<0.01$, Mann-Whitney
$U$ test). Moreover, $81.8 \%$ tumor counterparts displayed higher levels of KPNA2 than normal tissues, suggestive of a role as an oncoprotein in GC. Figure $3 \mathrm{~F}$ illustrates the cumulative survival curves of lower and higher expression groups of KPNA2 using a median value of 40 as the cutoff. Median follow-up duration of survivors $(n=53)$ was 84 months (range, 64-139 months). The five-year survival rate of the lower expression group was significantly greater than that of the higher expression group (78\% vs. $15.4 \%$, log-rank $p<0.0001)$. Relationships between KPNA2 expression and clinicopathological parameters of GC are summarized in Table 2. The characteristics of the study cases are listed $(n=77)$. Tumor size (maximum diameter) was, on average, $5.6 \mathrm{~cm}$ (median, $5.2 \mathrm{~cm}$; range, $0.3-20 \mathrm{~cm}$ ). Tumors were located in the proximal third of the stomach in $17(22.1 \%)$, middle third in $18(23.4 \%)$, distal third in $37(48.1 \%)$, and the whole stomach in 5 $(6.5 \%)$ cases. Histological tumor types were intestinal $(n=22,28.6 \%)$ and diffuse $(n=55,71.4 \%)$. As defined based on the depth of wall invasion, early GC (T1) was diagnosed in 16 (20.8\%), advanced GC (T2) (muscle proper and subserosa) in $12(15.6 \%)$, serosa (T3) in 37 (48.1\%), and invasion to adjacent organs (T4) in 12 $(15.6 \%)$ cases. Lymph node metastasis was diagnosed in $54(70.1 \%)$ cases. During surgery, liver metastasis was identified in $2(2.6 \%)$, peritoneal seeding in $18(23.4 \%)$,

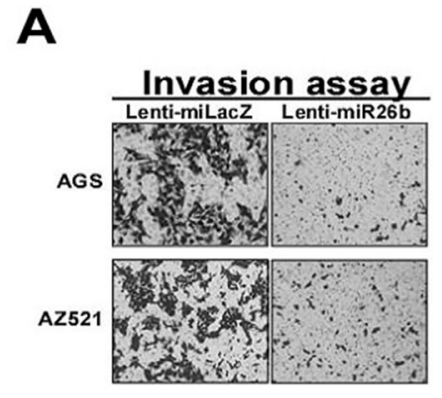

C

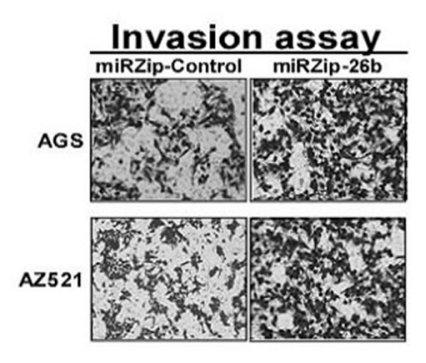

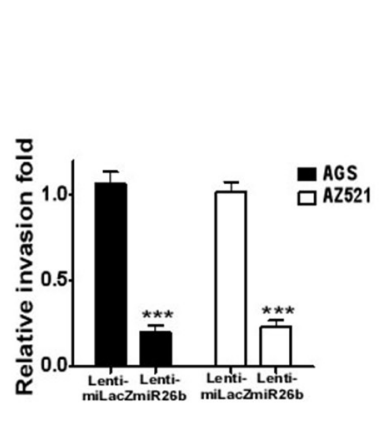

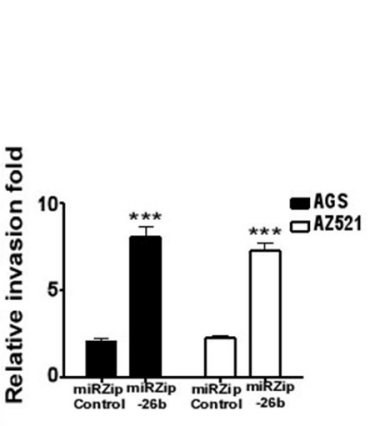

B
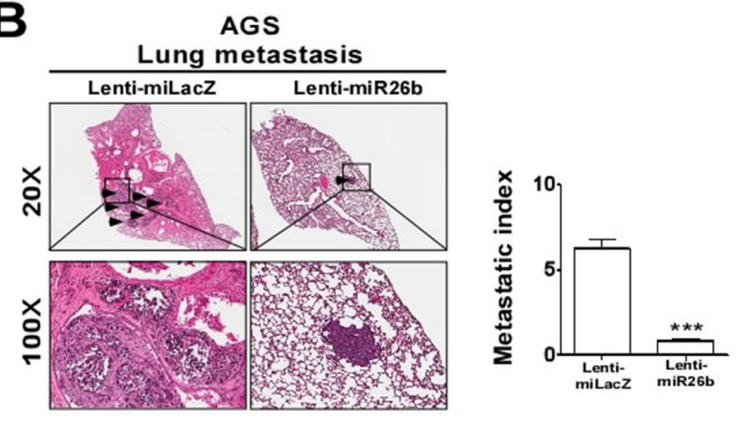

D

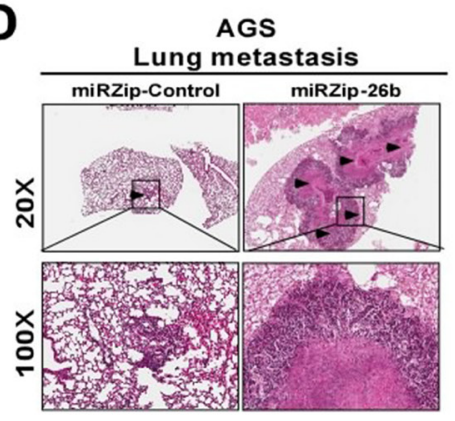

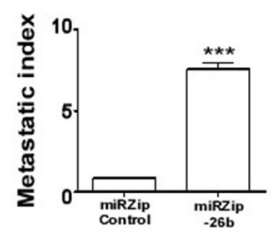

Figure 2: MiR-26b regulates cell invasion. Two days after infection (Lenti-miLacZ/Lenti-miR26b or miRZip-control/miRZip-26b virus), blasticidin $(8 \mu \mathrm{g} / \mathrm{ml})$ or puromycin $(4 \mu \mathrm{g} / \mathrm{ml})$ was added, and cells selected for two weeks. The number of cells invading the Matrigel to the lower chamber were determined after (A) miR-26b overexpression in AGS and AZ-521 cell lines. (B) MiR-26b-overexpressing AGS cells were injected into mouse tail vein $\left(1 \times 10^{6}\right.$ cells). Lung metastases were quantified (right) and images shown (left) $n=3$. All mice were sacrificed after 10 weeks. (C) Invasion activities of miR-26b-depleted AGS and AZ-521 cells. (D) Lung metastases from miR-26bdepleted AGS cells injected into mouse tail vein $\left(1 \times 10^{6}\right.$ cells). Lung metastases were quantified (right), and images shown (left) $n=3$. All mice were sacrificed after 16 weeks. Data are presented as mean values \pm SEM. Mann-Whitney $U$ test was used for comparison between the two groups. 
vascular invasion in 20 (26\%), lymphatic invasion in 46 $(59.7 \%)$, and perineural invasion in $28(36.1 \%)$ cases. In terms of pathological staging, $21(27.3 \%)$ cases were classified as stage I, 7 (9\%) as stage II, $24(31.2 \%)$ as stage III and $25(32.5 \%)$ as stage IV. Expression of KPNA2 in tumor tissues was not associated with age, gender or liver metastasis. Interestingly, KPNA2 levels were closely correlated with location $(p=0.026)$, gross type $(p<0.001)$, histological type $(p<0.001)$, depth of invasion $(p<0.001)$, and serosal invasion $(p<0.001)$. KPNA2 was more significantly downregulated in T3 and T4 groups whereby the serosal surface of the gastric wall
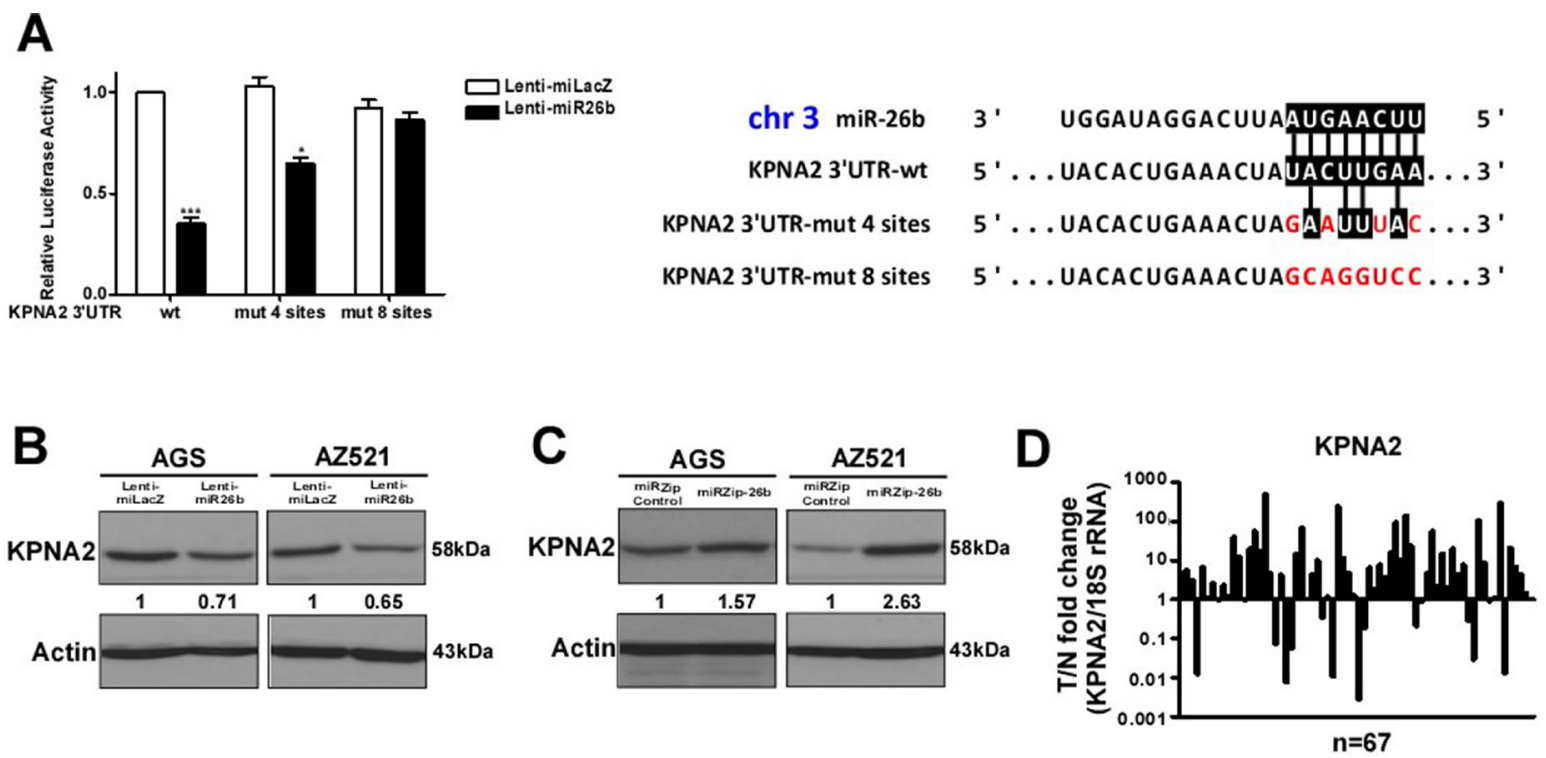
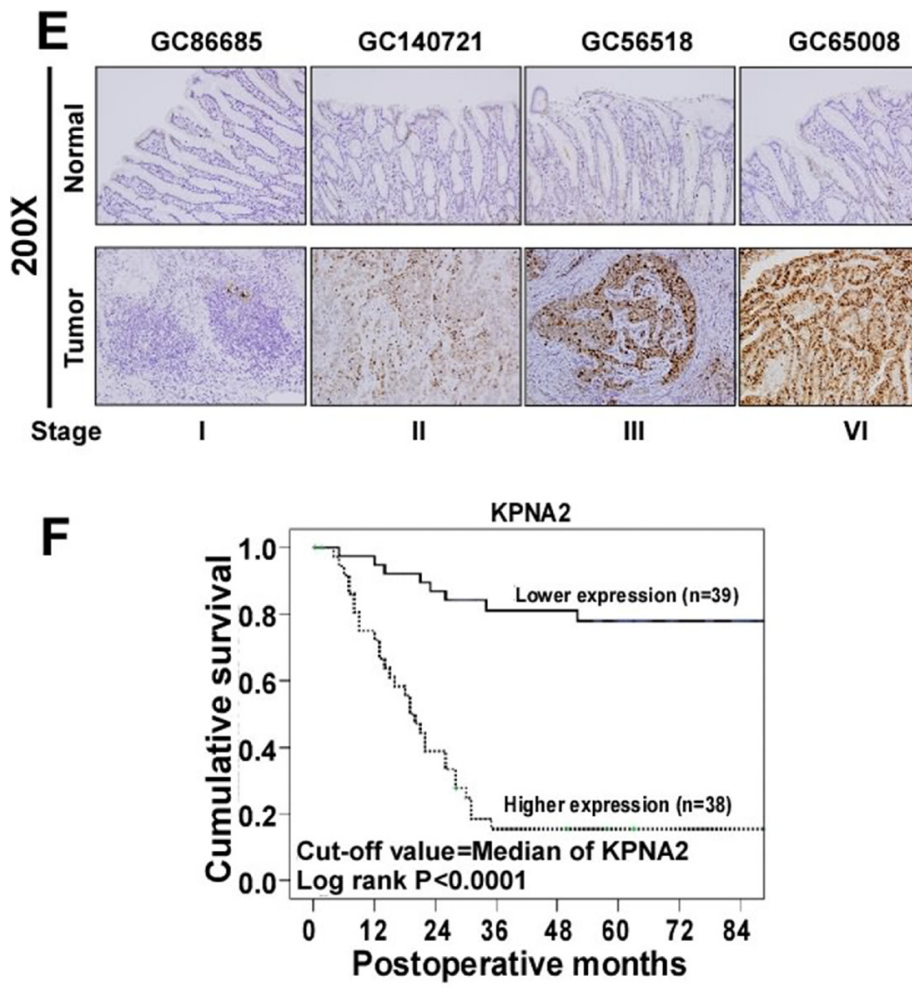

Figure 3: MiR-26b targets KPNA2. (A) Wild-type (wt) and mutant (mut) 3'UTRs of KPNA2 were cloned (right) and the luciferase reporter assay performed (left). Immunoblots of KPNA2 gene expression after (B) miR-26b overexpression or (C) depletion in GC clones. (D) KPNA2 mRNA expression was determined via RT-qPCR in T and N. (E) IHC staining (left, $N=77$ ). KPNA2 expression levels were determined based on IHC scores in T and N (right). Mann-Whitney U test was applied for comparison between the two groups. (F) KPNA2 expression vs five-year survival rate in $77 \mathrm{GC}$ tissues. Mann-Whitney $U$ test was used for comparison between the two groups. ${ }^{*} p<0.01$, $* * p<0.05, * * * p<0.001$. 
Table 2: Clinical characteriscs of 77 GC patients in two groups according to KPNA2 expression

\begin{tabular}{|c|c|c|c|c|c|c|c|}
\hline Parameters & No. & $\operatorname{Mean} \pm \mathrm{SE}^{\mathrm{a}}$ & $P^{b}$ & Parameters & No. & $\operatorname{Mean} \pm \mathbf{S E}^{\mathrm{a}}$ & $P^{\mathbf{b}}$ \\
\hline Age (years) & & & & \multicolumn{2}{|c|}{ Lymph node metastasis } & & \\
\hline$<65$ & 36 & $50.8 \pm 5.8$ & 0.586 & No (N0) & 23 & $27.0 \pm 7.6$ & $<0.001$ \\
\hline$\geq 65$ & 41 & $55.6 \pm 5.9$ & & Yes(N1,N2,N3) & 54 & $64.6 \pm 4.1$ & \\
\hline Gender & & & & \multicolumn{2}{|c|}{ Distant metastasis(pM) } & & \\
\hline Male & 41 & $50.3 \pm 5.9$ & 0.411 & No & 56 & $38.0 \pm 3.4$ & $<0.001$ \\
\hline Female & 36 & $56.1 \pm 5.9$ & & Yes & 21 & $94.3 \pm 6.5$ & \\
\hline Location & & & & \multicolumn{2}{|c|}{ Pathological stage(pStage) } & & \\
\hline Upper third & 17 & $51.8 \pm 10.1$ & 0.026 & Stages I & 21 & $15.2 \pm 2.5$ & $<0.001$ \\
\hline Middle third & 18 & $38.3 \pm 6.5$ & & Stages II & 7 & $30.0 \pm 3.1$ & \\
\hline Lower third & 37 & $55.7 \pm 5.6$ & & Stages III & 24 & $54.2 \pm 3.7$ & \\
\hline Whole & 5 & $96.0 \pm 15.0$ & & Stages IV & 25 & $91.2 \pm 5.8$ & \\
\hline Gross type & & & & Pathological stage & & & \\
\hline Localized & 29 & $30.0 \pm 6.0$ & $<0.001$ & Stages I, II & 28 & $18.9 \pm 2.3$ & $<0.001$ \\
\hline Infiltrative & 48 & $67.5 \pm 4.5$ & & Stages III, IV & 49 & $73.1 \pm 4.4$ & \\
\hline Histological type & & & & Liver metastasis & & & \\
\hline Intestinal & 22 & $33.2 \pm 7.5$ & $<0.001$ & No & 75 & $52.3 \pm 4.1$ & 0.303 \\
\hline Diffuse & 55 & $61.5 \pm 4.6$ & & Yes & 2 & $95.0 \pm 55.0$ & \\
\hline $\begin{array}{l}\text { Depth of } \\
\text { invasion(pT) }\end{array}$ & & & & Peritoneal seeding & & & \\
\hline $\mathrm{T} 1$ & 16 & $16.3 \pm 2.7$ & $<0.001$ & No & 59 & $43.2 \pm 4.3$ & $<0.001$ \\
\hline $\mathrm{T} 2$ & 12 & $23.3 \pm 4.0$ & & Yes & 18 & $86.7 \pm 6.6$ & \\
\hline $\mathrm{T} 3$ & 37 & $67.8 \pm 5.1$ & & Vascular invasion & & & \\
\hline $\mathrm{T} 4$ & 12 & $88.3 \pm 7.2$ & & No & 57 & $41.8 \pm 3.8$ & $<0.001$ \\
\hline Serosal invasion & & & & Yes & 20 & $86.5 \pm 8.1$ & \\
\hline No $(\mathrm{T} 1, \mathrm{~T} 2)$ & 28 & $22.1 \pm 4.0$ & $<0.001$ & Lymphatic invasion & & & \\
\hline Yes(T3,T4) & 49 & $71.2 \pm 4.4$ & & No & 31 & $30.0 \pm 5.8$ & $<0.001$ \\
\hline $\begin{array}{l}\text { Lymph node } \\
\text { status(pN) }\end{array}$ & & & & Yes & 46 & $69.1 \pm 4.5$ & \\
\hline N0 & 23 & $27.0 \pm 7.6$ & $<0.001$ & Perineural invasion & & & \\
\hline N1 & 25 & $49.6 \pm 5.0$ & & No & 49 & $40.4 \pm 4.9$ & $<0.001$ \\
\hline N2 & 12 & $65.0 \pm 5.7$ & & Yes & 28 & $76.1 \pm 5.5$ & \\
\hline \multirow[t]{3}{*}{$\mathrm{N} 3$} & 17 & $86.5 \pm 7.7$ & & KPNA2 (IHC score) & & & \\
\hline & & & & $<40$ (median) & 38 & & \\
\hline & & & & $\geq 40$ & 39 & & \\
\hline
\end{tabular}

aKPNA2 scores detected by IHC method in mean \pm standard error (SE). IHC; immunohistochemistry.

${ }^{\mathrm{b}} P$ values are analyzed by Pearson's chi-square test or Fisher's exact test.

was invaded by cancer, compared to T1 and T2 groups with no evident invasion $(p<0.001)$, as well as in relation to higher lymph node status $(p<0.001)$, lymph node metastasis $(p<0.001)$ and distant metastasis $(p<0.001)$. Moreover, KPNA2 was markedly decreased in patients displaying metastasis to the lymph node 
$(p<0.001)$ and more advanced pathologic stages (III and IV) of GC, compared to earlier pathologic stages (I and II) $(p<0.001)$, as well as those with peritoneal seeding $(p<0.001)$, vascular invasion $(p<0.001)$, lymphatic invasion $(p<0.001)$ and perineural invasion $(p<0.001)$. Since KPNA2 expression is negatively correlated with pathologic features (TNM stage), it is reasonable to hypothesize that loss of KPNA2 promotes GC metastasis. The prognostic significance of KPNA2 upregulation in GC was further determined via survival analysis.

\section{Validation of KPNA2 as an oncoprotein in GC}

KPNA2 is closely associated with GC metastasis, and identified as a putative pro-metastatic gene in several studies [10-12]. To further explore its function, KPNA2overexpressing and depleted AGS and AZ-521 cell lines were established. KPNA2 expression was decreased by 3.45- and 3.85-fold or increased 3.16- and 3.7-fold, respectively, as confirmed with western blot (Figure S5A). AGS and AZ-521 cells treated with shKPNA2 exhibited significantly decreased migration (4.35- and 3-fold, respectively) and invasion (3.45- and 2.71-fold, respectively) ( $p<0.01$, Mann-Whitney $U$ test), relative to those transfected with control vector (Figure S5B). Conversely, KPNA2 overexpression led to significantly increased migration and invasion (Figure S5C). Our data collectively support a pro-migratory and invasionstimulating role of KPNA2. To further explore the function of KPNA2 in vivo, the gene was either depleted or overexpressed in AGS cell lines. KPNA2-depleted cells exhibited a significant ( $p<0.01$, Mann-Whitney $U$ test) decrease in metastatic ability in vivo (6.52-fold), relative to those transfected with control vector (Figure S5D). Conversely, overexpression of KPNA2 led to markedly increased in vivo metastatic ability (5.07- fold) (Figure S5E). The data collectively support a pro-metastatic function of KPNA2.

\section{KPNA2 is involved in miR-26b-mediated suppression of cell migration and invasion}

To further confirm the association between miR$26 \mathrm{~b}$ and KPNA2 in GC metastasis, rescue experiments were performed. Re-expression of KPNA2 in a miR-26boverexpressing line or its knockdown in a miR-26b-depleted line was established (Figure S4). MiR-26b overexpression led to significant inhibition in cell migration and invasion, which was partially rescued upon re-expression of KPNA2 (Figure 4A). Conversely, the migration and invasion abilities of AGS were partially suppressed by shKPNA2 in miR-26b-depleted line (Figure 4B).

\section{A}
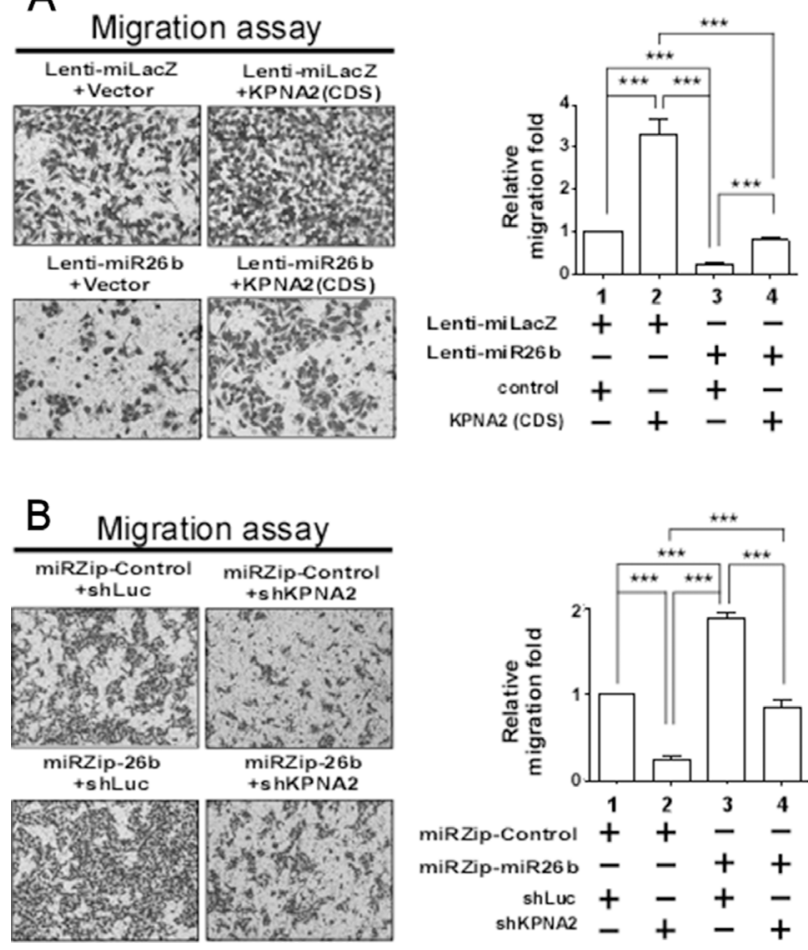
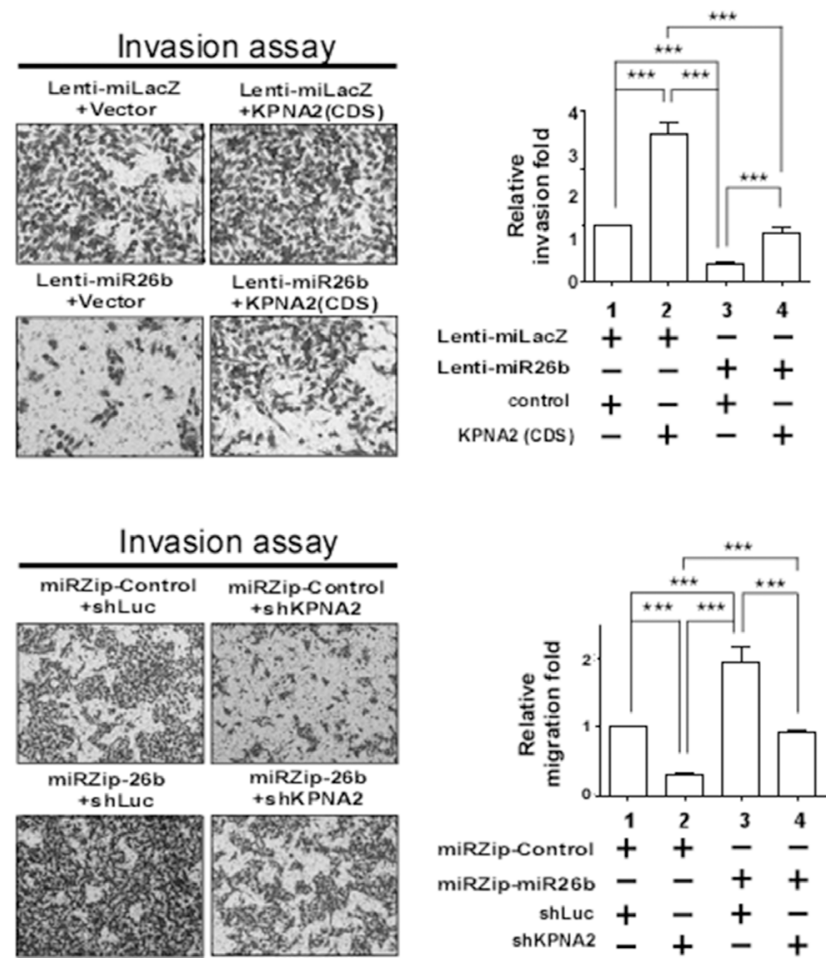

Figure 4: Alterations in KPNA2 expression influence miR-26b-mediated migration and invasion Migration and invasion assays using stable AGS and AZ-521 cells. (A) GC clones stably overexpressing miR-26b were transfected with KPNA2 or control plasmid. (B) MiR-26b-depleted clones were transfected with shKPNA2 or control plasmid. Data are presented as mean values \pm SEM. Mann-Whitney $U$ test was used for comparisons between the two groups. 


\section{Downregulation of miR-26b is inversely correlated with KPNA2 expression through CagA and c-jun}

An inverse association between KPNA2 protein or mRNA and miR-26b expression was observed in clinical specimens $(n=71 ; r=-0.67, p<0.001$ or $n=54 ; r=-0.27$, $p<0.05$, Pearson correlation, Figure 5A). To establish the mechanisms underlying suppression of miR-26b in $\mathrm{GC}$, we explored the potential regulatory factors of miR-26b. To date, a number of risk factors for gastric cancer, including Helicobacter pylori $(\mathrm{Hp})$ infection, chromosomal instability and genetic alterations, have been identified in GC [13-15]. Therefore, we attempted to determine the factors accounting for lower expression of miR-26b. Based on previous findings, Helicobacter pylori $(\mathrm{Hp})$ virulence factor CagA (cytotoxin-associated gene A) associated with GC was selected for testing [16]. RT-qPCR analysis revealed 5.87 and 4.43-fold downregulation of miR-26b in CagA-transformed AGS/ AZ521 cells (Figure 5C), respectively, indicating that miR-26b is suppressed by CagA. However, the current experiments do not rule out the involvement of other potential factors. Recently, several groups have identified KPNA2 as a nuclear transport receptor protein $[17,18]$. Accordingly, we tested the interactions of KPNA2 protein with other factors, including c-jun, c-myc, p53 and E2F1. Notably, c-myc, p53 and E2F1 levels in cell lines stably expressing miR-26b remained unchanged on a western blot (data not shown), while c-jun was significantly suppressed by miR-26b. The effect of miR$26 \mathrm{~b}$ on c-jun was further examined in the two cell lines. Simultaneous downregulation of KPNA2 and c-Jun proteins was observed in miR-26b-overexpressing cells, suggesting a critical axis of miR-26b-targeted KPNA2/cjun for $\mathrm{GC}$ metastasis and vice versa (Figure 5B, left). In addition, KPNA2 co-immunoprecipitated (CoIP) with c-jun (Figure 5B, right). Thus, miR-26b may be a useful independent prognostic tumor marker to predict survival and GC metastasis. Augmentation of miR-26b signaling or function presents a potential therapeutic strategy for inhibition of GC metastasis (Figure 5D).

\section{DISCUSSION}

MiR-26b is downregulated in various tumor types [19-25], suggesting an important role in tumorigenesis and tumor progression. Previous studies have reported that miR26b has anti-metastasis (PTEN, EphA2, LARP1, CTGF, PFKFB3, Smad1, TNKS1BP1, CPSF7, COL12A1, Nampt, COX-2 pathway targets), anti-proliferative (CDK8, PTGS2, pRb, CHD1, KPNA2, PTEN-AKT pathway targets), antisurvival (Nampt), anti-epithelial-mesenchymal transition (USP9X), pro-chemosensitivity (NF- $\mathrm{KB}$ signaling, TAK1 and TAB3), glycolytic metabolism (PFKFB3) and antiapoptosis (Smad4, SLC7A11) functions [7, 26-39].
$\mathrm{Li}$ et al. [45] reported roles of miR-26b in hepatocellular carcinoma (HCC) cell proliferation, migration, and invasion, and confirmed that EphA2 is a direct target. Additionally, miR-26b was shown to downregulate c-Myc and Cyclin D1 expression [35]. The group of Zhu showed that miR-221 and miR-26b enhance mesenchymal stem cell (MSC) migration towards hepatocyte growth factor (HGF) through activation of $\mathrm{PI} 3 \mathrm{~K} /$ Akt signaling and targeting phosphatase and tensin homolog deleted on chromosome ten (PTEN) in vitro [26]. Downregulation of miR-26b modulates chemoresistance and migration through association with PTEN in non-small cell lung cancer cells and human carcinoma tissues [36]. La-related protein 1 (LARP1) was identified as a regulatory target of miR-26a/b inhibiting prostate cancer (PCa) cell invasion by Kato et al. [37]. Duan and co-workers found that downregulation of miR-26b in osteosarcoma elevates the levels of CTGF and Smad1, facilitating metastasis in osteosarcoma (os) [27]. Reduced miR-26b expression promoted breast fibroblast migration and invasion. Three novel miR-26b targets were identified (TNKS1BP1, CPSF7, COL12A1), and the expression of each in cancer stroma shown to be significantly associated with breast cancer recurrence [38]. Another study reported that miR$26 \mathrm{~b}$ acts as a tumor suppressor in glioma and directly regulates EphA2 expression [39].

The role of miR-26b in GC progression remains to be established. In the present study, we identified miR$26 \mathrm{~b}$ as a novel anti-metastatic miRNA in GC significantly associated with clinically advanced stages and lymph node metastasis. Clinicopathological data indicate that lower expression of miR-26b is associated with GC progression. Additionally, lymph node metastasis is an initial step of GC progression that is associated with clinical stage, prognosis, and survival of GC patients [40]. Recently, miRNAs linked to lymph node metastasis of GC, such as miR-218, miR146a, miR-429, and miR-370, have been identified [4144]. These findings may provide new insights into ways to design improved therapeutic strategies for GC patients with metastasis. Data from the current study revealed that downregulation of miR-26b enhances GC cell migration and invasion in vitro and metastasis in vivo. KPNA2 was further identified as a direct target of miR-26b. In terms of the underlying mechanism, our experiments showed that CagA of $H p$ stimulates miR-26b downregulation, although further studies are essential to clarify any potential additional factors involved. Notably, miR-26b suppressed KPNA2, both at the mRNA and protein level. KPNA2 (also designated importin $\alpha-1$ or RAG cohort 1) belongs to a member of the karyopherin $\alpha$ family and plays a key role in the nuclear import of cargo proteins. KPNA2 is implicated in a multitude of cellular processes, including differentiation, transcriptional regulation, immune response, viral infection, cellular maintenance and carcinogenesis. Moreover, aberrant KPNA2 expression has been observed in several cancer types, suggesting a potential role in 
tumorigenesis [45]. Several studies have shown that KPNA2 acts as an oncogene [10-12], while others report a tumor suppressor role [46]. Here, we demonstrated that KPNA2 is upregulated in GC tissues and increases cell mobility, supporting a pro-metastatic function. Kim et al. [47] identified the transcription factor, Sp1, as a common regulator of NCT (nucleocytoplasmic trafficking) genes, including various nucleoporins, importins, exportins, and Ran GTPase cycle-related genes. Our western blot and CoIP analyses additionally led to the identification of c-Jun as a downstream target of KPNA2. c-Jun is a proto- oncogene belonging to a nuclear phosphoprotein family, which heterodimerizes with c-fos to form the transcription factor complex, AP-1. Overexpression of c-fos promotes cell invasion and migration [48]. Furthermore, the public NCBI web GEO profile documents higher KPNA2 expression in 22 primary advanced GC tissues, compared to 8 normal controls $($ mean $=119.9,35.3)$. Similar results have been obtained from the Public IHC database (http:// www.proteinatlas.org/ $)(N=9, \mathrm{~T}=22)$. However, the precise roles of KPNA2 in cancer cells require further investigation.
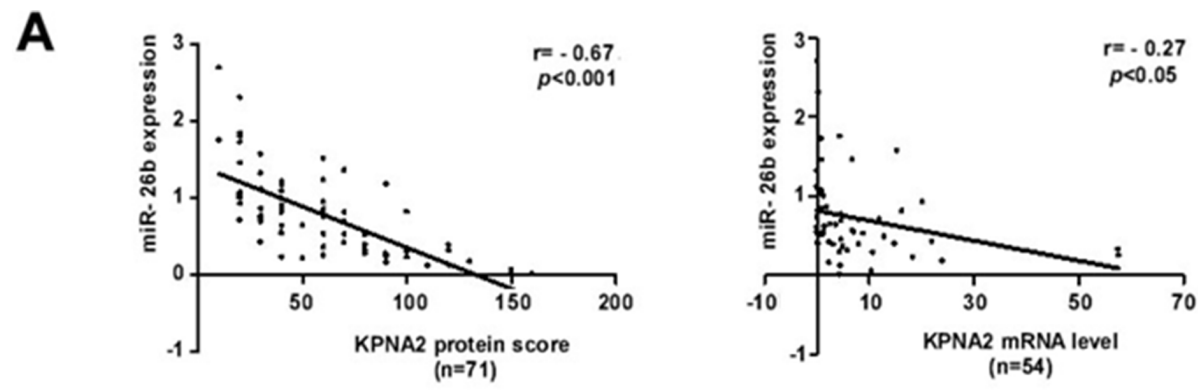

B
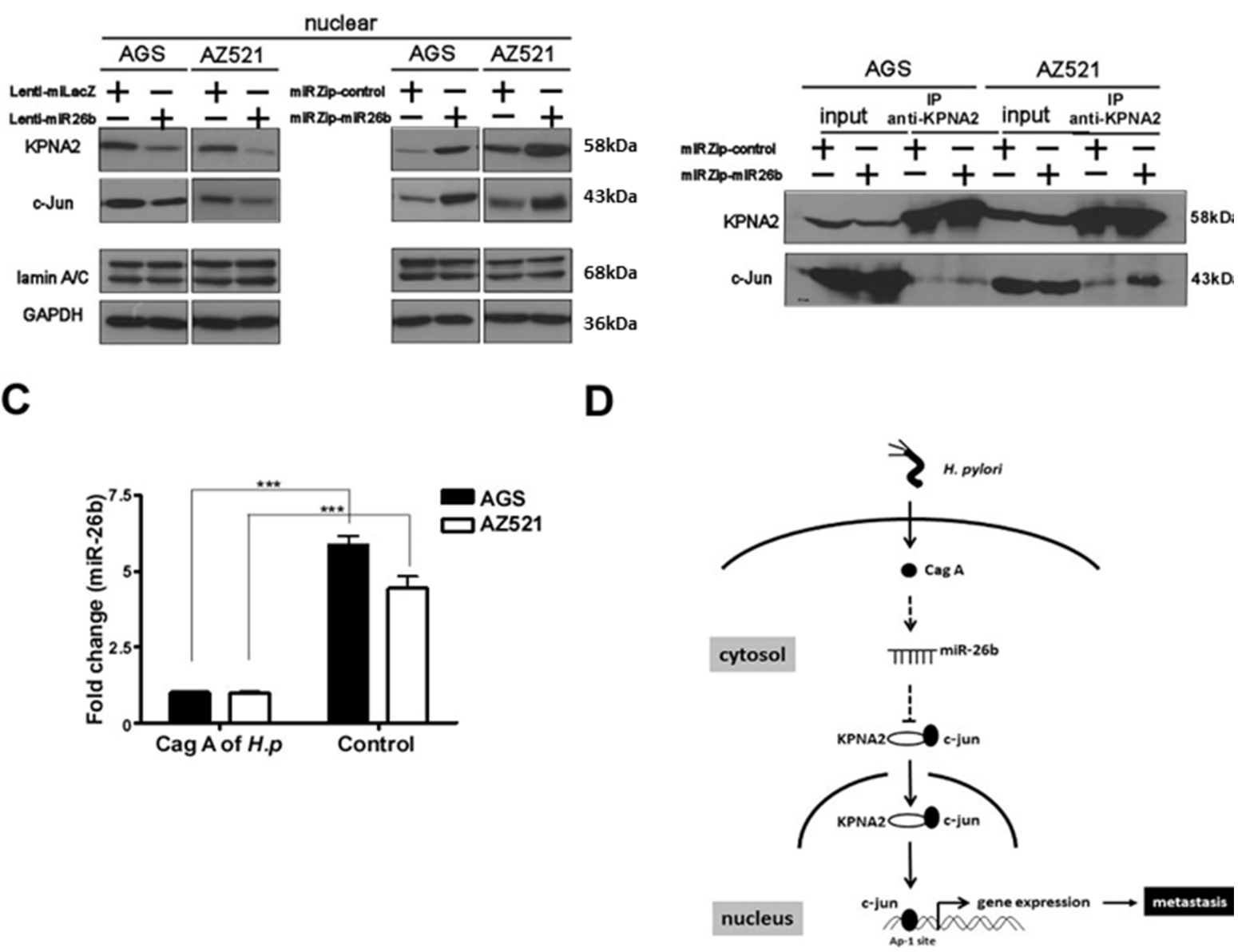

Figure 5: Downregulation of KPNA2 is inversely correlated with miR-26b expression in GC tissues. The relationship between miR-26b and KPNA2 protein levels was assessed using (A) RT-qPCR and IHC analyses. (B) Cag A stimulates miR-26b expression (C) Alterations in miR-26b expression influence KPNA2 and c-Jun (left panel) CoIP (right panel) (D) Diagram of miR-26b signaling. Data are presented as means \pm SEMs. Mann-Whitney $U$ test was applied for comparison between the two groups. 
In summary, our results show that miR-26b, an important metastatic suppressor miRNA, is downregulated in relation to lymph node metastasis progression in GC. Moreover, miR-26b and histological type, a pathological parameter, have independent prognostic value for 5-year cumulative survival, supporting a potential role of metastasis-suppressing miR-26b as a novel prognostic biomarker. Ectopically expressed miR-26b inhibits GC cell invasion and metastasis through direct targeting and negative regulation of KPNA2, and its frequent downregulation is suggested to be part of the mechanism underlying metastasis and progression. Therefore, overexpression of miR-26b or suppression of KPNA2 may have therapeutic potential in GC patients with metastasis. Further research is warranted to establish the potential of miR-26b as a prognostic and therapeutic agent.

\section{MATERIALS AND METHODS}

\section{Patients}

All 106 patients (59 males, 47 females; age: 63.5 years, range, 28-84 years) diagnosed pathologically with GC at the Chang Gung Memorial Hospital (CGMH) from 2000 to 2006 were enrolled in the study. Individual patients were subjected to gastric resection (74 partial gastrectomy and 32 total gastrectomy) as described previously [6]. This study was approved by the Institutional Review Board (IRB No. 102-3017C).

\section{Clinicopathology}

Resected GC specimens were examined pathologically using criteria of the 6th edition of the American Joint Committee on Cancer (AJCC) (TNM) classification system and the Japanese General Rules for GC study [49]. Patient parameters included age, gender, location, gross type, histological type, depth of invasion, serosal invasion, lymph node status, lymph node metastasis, distant metastasis, pathological stage, liver metastasis, peritoneal seeding, vascular invasion, lymphatic invasion, and perineural invasion. After release, all patients had periodic follow-up visits at the outpatient department of CGMH until death or beginning of preparation of this study.

\section{GC tissues}

Fresh GC and paired normal tissues were collected immediately following gastric resection. Specimens were immediately snap-frozen in individual vials using liquid nitrogen. Frozen specimens were stored at $-70^{\circ} \mathrm{C}$ in a tumor bank until use.

\section{RNA extraction}

Total RNA were extracted using TRIzol ${ }^{\circledR}$ Reagent (Invitrogen, Carlsbad, CA). The concentrations of all RNA samples were quantified using NanoDrop 1000 (Nanodrop Technologies Inc., Wilmington, DE).

\section{RT-qPCR}

We assessed miR-26b and KPNA2 mRNA expression patterns as described earlier in the same patient groups [6]. Briefly, to quantify miRNA transcripts, total RNA was extracted from cells using the TRIzol solution kit (Life Technology Inc., Carlsbad, CA, USA). RT-qPCR products were detected using SYBR Green, as described previously, with U6 as the internal control for miRNA [6, 50, 51]. Fluorescence emitted by SYBR green was examined using the ABI PRISM 7500 sequence detection system (Applied Biosystems, Werrington, UK). Sequences of primers used for RT-qPCR were as follows: KPNA2 (forward primer, 5'-TGCTACTTCTCCGCTGCAGG-3', and reverse primer, 5'-CTGGCAGCTTGAGTAGCTTG-3'); human 18s rRNA (forward primer, 5'-CGAGCCGCCTGGATACC-3', and reverse primer, 5'-CCTCAGTT CCGAAAACCAACAA-3').

\section{Cell culture}

Human GC lines (AGS and AZ-521) were obtained from American Type Culture Collection (ATCC) and routinely grown in Roswell Park Memorial Institute medium (RPMI) 1640 (Invitrogen) supplemented with $10 \%(\mathrm{v} / \mathrm{v})$ fetal bovine serum (FBS) (Invitrogen), $100 \mathrm{IU} / \mathrm{ml}$ penicillin $\mathrm{G}$ and $100 \mathrm{mg} / \mathrm{ml}$ streptomycin sulfate (SigmaAldrich). Cells were cultured at $37^{\circ} \mathrm{C}$ in a humidified atmosphere containing $5 \% \mathrm{CO}_{2}$.

\section{Establishing a miR-26b-overexpression cell line}

Cells were transfected with BLOCK-iT Pol $11 \mathrm{miR}$ RNAi Expression vectors (Invitrogen), according to a previously reported protocol $[6,51]$.

\section{Establishing a miR-26b-depleted cell line}

Cells were transfected with the miRZip-26b lentivector (SBI System, BioScience, Mountain View, CA) or negative control (miRZip lentivector), according to a previous protocol $[6,51]$.

\section{In vivo metastatic assays}

Male severe combined immunodeficiency (SCID, C.B17/Icr-scid) mice 4-6 weeks of age were injected with $1 \times 10^{6}$ cells $/ 200 \mu 1$ PBS via the tail vein and sacrificed after 8 weeks. All animal assays were performed in accordance with the guidelines of U.S. National Institutes of Health and the Chang-Gung Institutional Animal Care and Use Committee Guide for Care and Use of Laboratory Animals. This study was conducted under the approval of Chang-Gung Institutional Animal Care and Use Committee (IACUC Approval No. CGU13-127). Lung metastasis was 
quantified by counting the total tissue area per lung section (A1) and metastasis present in the same area (A2). The metastatic index was calculated based on the A2/A1 ratio.

\section{Luciferase assay}

All transient transfections were conducted using TurboFect Reagent (Invitrogen) and pMIR-report plasmids (Ambion, Foster City, CA) as reporter constructs. Cells were harvested $48 \mathrm{~h}$ after transfection in lysis buffer and subsequently assayed for luciferase activity (Luciferase Assay System, Promega, WI) using $\beta$-galactosidase as the internal control. Cleavage stimulation factor subunit 2 (CSTF2), karyopherin alpha 2 (KPNA2), leucinerich pentatricopeptide repeat containing (LRPPRC), developmentally regulated GTP binding protein 1 (DRG1), v-yes-1 Yamaguchi sarcoma viral related oncogene homolog (LYN), splicing factor proline/glutamine-rich (SFPQ), aldehyde dehydrogenase 5 family, member A1 (ALDH5A1), glia maturation factor beta (GMFB), solute carrier family 12, member 2 (SLC12A2), 1-acylglycerol3-phosphate O-acyltransferase 5 (AGPAT5) and Death inducer-obliterator 1 (DIDO1) were assayed. Luciferase reporter genes driven by 3'UTRs of computationally predicted (wt-3'UTR) and mutated KPNA2 (mt-3'UTR) were generated via PCR amplification from human genomic DNA and subsequently cloned between $M l u$ I and Spe I sites within the 3'UTR of pMIR-report plasmids. The primer sequences for miR-26b binding sites of 11 putative target genes are provided (Supplementary Table S1).

\section{Immunohistochemistry (IHC)}

Paraffin-embedded tissues ( $5 \mu \mathrm{m}$ thickness) were prepared for different GC samples, and IHC performed to detect KPNA2 (Epitomics, Burlingame, CA; dilution 1:150), as described previously [52].

\section{In vitro metastatic assays}

To examine the effects of miR-26b and KPNA2 overexpression or depletion on the migratory and invasive activities of GC cell lines, the rapid in vitro Transwell assay (Becton-Dickinson, Franklin Lakes, NJ) with $8 \mathrm{~mm}$ membrane pore size chamber inserts non-matrigel-coated (migration assay) or matrigel-coated (invasion assay) was performed for quantifying potential tumor cell migration or invasion [53]. Migratory or invasive cells were counted using Image J software.

\section{Western blot analysis}

Total cell lysates from GC and paired normal tissues or cell lines were prepared, and protein concentrations determined using a previously described method [52]. The intensities of immunoreactive bands were quantified using Image Gauge software (Fuji Film, Tokyo, Japan) on a densitometer.

\section{Gene Ontology database}

We used TargetScan, a miRBase algorithm, combined with differentially expressed proteins from the GC database as well as isobaric tags for relative and absolute quantification (iTRAQ) datasets from our laboratory to identify putative protein- coding gene targets of miR-26b. A list of genes related to oncogenic function was compiled based on publicly available databases (Gene Ontology, http://www.geneontology.org) and recent literature. Consequently, 11 candidate genes were selected (the gene list and corresponding Gene Ontology Database are presented in Supplementary Table S1).

\section{Overexpression/depletion of KPNA2 in GC cell lines}

KPNA2 cDNA (no 3'UTR) was amplified using RTPCR and cloned into the pcDNA3 vector. Transfection of pcDNA3-KPNA2 was performed using TurboFect Reagent (Invitrogen). After $24 \mathrm{~h}$ of incubation, cells were transferred to G418 medium for selection. KPNA2 overexpression was confirmed with western blot analysis. Cells transfected with the pcDNA3 vector served as the control. Alternatively, KPNA2 was depleted using specific shRNA, with the aim of determining its function. Clones of shRNA targeting KPNA2 (TRCN0000065309, TRCN00000286475) were purchased from the National RNA Interference Core Facility (Academia Sinica, Taiwan). Transfection of shRNA targeting endogenous KPNA2 genes was performed using TurboFect Reagent (Invitrogen). After $24 \mathrm{~h}$ of incubation, cells were transferred to medium containing puromycin for selection. Following 2 weeks of selection, specific suppression of the KPNA2 gene was confirmed with western blot analysis.

\section{Statistical analysis}

The Mann-Whitney U-test or Fisher's exact test was used for between-group comparisons where appropriate, and correlation between the results obtained with the two different analyses determined with Spearman's test. Follow-up studies of patients were performed until the time of writing or patient death. Cancer-specific survival outcomes were evaluated by applying the Kaplan-Meier method for all patients, except those who died from surgical complications. The log-rank test was used to compare the prognostic significance of individual variables on survival. Cox's proportional hazards model was applied in multivariate analysis to identify independent predictors of survival. $P$-values $<0.05$ were considered statistically significant.

\section{Abbreviations}

AGPAT5: 1-acylglycerol-3-phosphate O-acyltransferase 5; ALDH5A1: aldehyde dehydrogenase 5 family, member A1; 
Cag A: cytotoxin-associated gene A; CDS: coding sequence; CGMH: Chang Gung Memorial Hospital; CI: confidence interval; CoIP: co-immunoprecipitate; CSTF2: cleavage stimulation factor subunit 2; DIDO1: death inducer-obliterator 1; DRG1: developmentally regulated GTP binding protein 1; GC: gastric cancer; GMFB: glia maturation factor beta; Hp: Helicobacter pylori; HGF: hepatocyte growth factor; HR: hzards ratio; IHC: immunohistochemistry; iTRAQ: isobaric tags for relative and absolute quantitation; KPNA2: karyopherin alpha 2; LARP1: La-related protein 1; LRPPRC: leucine-rich pentatricopeptide repeat containing; LYN: v-yes-1 Yamaguchi sarcoma viral related oncogene homolog; MiRNAs: MicroRNAs; MSCs: mesenchymal stem cells; NCT: nucleocytoplasmic trafficking; NSCLC: non-small cell lung cancer; PCa: prostate cancer; PTEN: phosphatase and tensin homologue deleted on chromosome ten; RT-qPCR: real-time reverse transcription quantitative polymerase chain reaction; SCID: severe combined immunodeficiency; SFPQ: splicing factor proline/glutamine-rich; SLC12A2: solute carrier family 12 , member 2 ; TNM stage: tumor-nodemetastasis stage; UTR: untranslated regions

\section{ACKNOWLEDGMENTS}

The authors thank Dr. Ying Liang for immunohistochemistry and pathological comments.

\section{GRANT SUPPORT}

This work was supported by grants from ChangGung, Taoyuan, Taiwan (CMRPF1C0151, CMRPF1C0152, CMRPF1C0153, CMRPG6D0011, CMRPG6D0012) and the National Science Council of the Republic of China (NSC 100-2314-B-182A-074).

\section{CONFLICTS OF INTEREST}

The authors declare no conflicting financial interests.

\section{REFERENCES}

1. Jemal A, Siegel R, Ward E, Hao Y, Xu J, Murray T, Thun MJ. Cancer statistics, 2008. CA Cancer J Clin. 2008; 58:71-96.

2. Department of Health T. (Department of Health, Taiwan. Cause of death statistics. 2010 [assessed April 7th 2010]. 2010.

3. Tsujimoto H, Ono S, Ichikura T, Matsumoto Y, Yamamoto J, Hase K. Roles of inflammatory cytokines in the progression of gastric cancer: friends or foes? Gastric Cancer. 2010; $13: 212-221$.

4. Ventura A, Jacks T. MicroRNAs and cancer: short RNAs go a long way. Cell. 2009; 136586-591.

5. Kent OA, Mendell JT. A small piece in the cancer puzzle: microRNAs as tumor suppressors and oncogenes. Oncogene. 2006; 25:6188-6196.
6. Tsai MM, Wang CS, Tsai CY, Chen CY, Chi HC, Tseng YH, Chung PJ, Lin YH, Chung IH, Lin KH. MicroRNA-196a/$196 \mathrm{~b}$ promote cell metastasis via negative regulation of radixin in human gastric cancer. Cancer Lett. 2014; 351:222-231.

7. Zhang C, Tong J, Huang G. Nicotinamide phosphoribosyl transferase (Nampt) is a target of microRNA-26b in colorectal cancer cells. PloS one. 2013; 8:e69963.

8. Tan S, Ding K, Li R, Zhang W, Li G, Kong X, Qian P, Lobie PE, Zhu T. Identification of miR-26 as a key mediator of estrogen stimulated cell proliferation by targeting CHD1, GREB1 and KPNA2. Breast Cancer Res. 2014; 16:R40.

9. Zhang Z, Wang J, Lu X. An integrated study of natural hydroxyapatite-induced osteogenic differentiation of mesenchymal stem cells using transcriptomics, proteomics and microRNA analyses. Biomed Mater. 2014; 9:045005.

10. Wang CI, Wang CL, Wang CW, Chen CD, Wu CC, Liang Y, Tsai YH, Chang YS, Yu JS, Yu CJ. Importin subunit alpha-2 is identified as a potential biomarker for non-small cell lung cancer by integration of the cancer cell secretome and tissue transcriptome. Int J Cancer. 2011; 128:2364-2372.

11. Noetzel E, Rose M, Bornemann J, Gajewski M, Knuchel R, Dahl E. Nuclear transport receptor karyopherin-alpha2 promotes malignant breast cancer phenotypes in vitro. Oncogene. 2012; 31:2101-2114.

12. Jensen JB, Munksgaard PP, Sorensen CM, Fristrup N, Birkenkamp-Demtroder K, Ulhoi BP, Jensen KM, Orntoft TF, Dyrskjot L. High expression of karyopherin-alpha2 defines poor prognosis in non-muscle-invasive bladder cancer and in patients with invasive bladder cancer undergoing radical cystectomy. Eur Urol. 2011; 59:841-848.

13. Barreto-Zuniga R, Maruyama M, Kato Y, Aizu K, Ohta H, Takekoshi T, Bernal SF. Significance of Helicobacter pylori infection as a risk factor in gastric cancer: serological and histological studies. J Gastroenterol. 1997; 32:289-294.

14. Kim KM, Kwon MS, Hong SJ, Min KO, Seo EJ, Lee KY, Choi SW, Rhyu MG. Genetic classification of intestinaltype and diffuse-type gastric cancers based on chromosomal loss and microsatellite instability. Virchows Arch. 2003; 443:491-500.

15. Yasui W, Oue N, Kuniyasu H, Ito R, Tahara E, Yokozaki H. Molecular diagnosis of gastric cancer: present and future. Gastric Cancer. 2001; 4:113-121.

16. Liu NN, Wang Y, Wu Q. [Jianpi jiedu recipe inhibited Helicobacter pylori-induced the expression of cyclooxygenase-2 via p38MAPK/ATF-2 signal transduction pathway in human gastric cancer cells]. Zhongguo Zhong Xi Yi Jie He Za Zhi. 2011; 31:926-931.

17. Wang CI, Chien KY, Wang CL, Liu HP, Cheng CC, Chang YS, Yu JS, Yu CJ. Quantitative proteomics reveals regulation of karyopherin subunit alpha-2 (KPNA2) and its potential novel cargo proteins in nonsmall cell lung cancer. Mol Cell Proteomics. 2012; 11:1105-1122. 
18. Huang L, Wang HY, Li JD, Wang JH, Zhou Y, Luo RZ, Yun JP, Zhang Y, Jia WH, Zheng M. KPNA2 promotes cell proliferation and tumorigenicity in epithelial ovarian carcinoma through upregulation of c-Myc and downregulation of FOXO3a. Cell Death Dis. 2013; 4:e745.

19. Li FQ, Xu B, Wu YJ, Yang ZL, Qian JJ. Differential microRNA expression in signet-ring cell carcinoma compared with tubular adenocarcinoma of human gastric cancer. Genetics and molecular research. 2015; 14:739-747.

20. Sandhu R, Rivenbark AG, Mackler RM, Livasy CA, Coleman WB. Dysregulation of microRNA expression drives aberrant DNA hypermethylation in basal-like breast cancer. Int J Oncol. 2014; 44:563-572.

21. Shah MS, Davidson LA, Chapkin RS. Mechanistic insights into the role of microRNAs in cancer: influence of nutrient crosstalk. Frontiers in genetics. 2012; 3:305.

22. Solomides CC, Evans BJ, Navenot JM, Vadigepalli R, Peiper SC, Wang ZX. MicroRNA profiling in lung cancer reveals new molecular markers for diagnosis. Acta cytologica. 2012; 56:645-654.

23. Zhao L, Sun Y, Hou Y, Peng Q, Wang L, Luo H, Tang X, Zeng Z, Liu M. MiRNA expression analysis of cancerassociated fibroblasts and normal fibroblasts in breast cancer. Int J Biochem Cell Biol. 2012; 44:2051-2059.

24. Bakre A, Mitchell P, Coleman JK, Jones LP, Saavedra G, Teng M, Tompkins SM, Tripp RA. Respiratory syncytial virus modifies microRNAs regulating host genes that affect virus replication. J Gen Virol. 2012; 93:2346-2356.

25. Hsu CM, Lin PM, Wang YM, Chen ZJ, Lin SF, Yang MY. Circulating miRNA is a novel marker for head and neck squamous cell carcinoma. Tumour biology: The J Int Soc Oncodev Biol Med. 2012; 33:1933-1942.

26. Zhu A, Kang N, He L, Li X, Xu X, Zhang H. MiR-221 and miR-26b regulate chemotactic migration of MSCs toward HGF through activation of Akt and FAK. J Cell Biochem. 2015.

27. Duan G, Ren C, Zhang Y, Feng S. MicroRNA-26b inhibits metastasis of osteosarcoma via targeting CTGF and Smad1. Tumour biology: The J Int Soc Oncodev Biol Med. 2015.

28. Du JY, Wang LF, Wang Q, Yu LD. miR-26b inhibits proliferation, migration, invasion and apoptosis induction via the downregulation of 6-phosphofructo-2-kinase/fructose2,6-bisphosphatase-3 driven glycolysis in osteosarcoma cells. Oncology reports. 2015; 33:1890-1898.

29. Cao J, Guo T, Dong Q, Zhang J, Li Y. miR-26b is downregulated in human tongue squamous cell carcinoma and regulates cell proliferation and metastasis through a COX-2dependent mechanism. Oncology reports. 2015; 33:974-980.

30. Liu J, Du X, Zhou J, Pan Z, Liu H, Li Q. MicroRNA-26b functions as a proapoptotic factor in porcine follicular Granulosa cells by targeting Sma-and Mad-related protein 4. Biology of reproduction. 2014; 91:146.
31. Li J, Li X, Kong X, Luo Q, Zhang J, Fang L. MiRNA-26b inhibits cellular proliferation by targeting CDK8 in breast cancer. Int J Clin Exp Med. 2014; 7:558-565.

32. Zhao N, Wang R, Zhou L, Zhu Y, Gong J, Zhuang SM. MicroRNA-26b suppresses the NF-kappaB signaling and enhances the chemosensitivity of hepatocellular carcinoma cells by targeting TAK1 and TAB3. Molecular cancer. 2014; 13:35.

33. Li J, Kong X, Zhang J, Luo Q, Li X, Fang L. MiRNA-26b inhibits proliferation by targeting PTGS2 in breast cancer. Cancer cell Int. 2013; 13:7.

34. Zhu Y, Lu Y, Zhang Q, Liu JJ, Li TJ, Yang JR, Zeng C, Zhuang SM. MicroRNA-26a/b and their host genes cooperate to inhibit the G1/S transition by activating the pRb protein. Nucleic acids Res. 2012; 40:4615-4625.

35. Li H, Sun Q, Han B, Yu X, Hu B, Hu S. MiR-26b inhibits hepatocellular carcinoma cell proliferation, migration, and invasion by targeting EphA2. Int J Clin Exp Pathol. 2015; 8:4782-4790.

36. Liang N, Zhou X, Zhao M, Zhao D, Zhu Z, Li S, Yang H. Down-regulation of microRNA-26b modulates non-small cell lung cancer cells chemoresistance and migration through the association of PTEN. Acta biochimica et biophysica Sinica. 2015; 47:530-538.

37. Kato M, Goto Y, Matsushita R, Kurozumi A, Fukumoto I, Nishikawa R, Sakamoto S, Enokida H, Nakagawa M, Ichikawa T, Seki N. MicroRNA-26a/b directly regulate La-related protein 1 and inhibit cancer cell invasion in prostate cancer. Int J Oncol. 2015; 47:710-718.

38. Verghese ET, Drury R, Green CA, Holliday DL, Lu X, Nash C, Speirs V, Thorne JL, Thygesen HH, Zougman A, Hull MA, Hanby AM, Hughes TA. MiR-26b is down-regulated in carcinoma-associated fibroblasts from ER-positive breast cancers leading to enhanced cell migration and invasion. $\mathrm{J}$ Pathol. 2013; 231:388-399.

39. Wu N, Zhao X, Liu M, Liu H, Yao W, Zhang Y, Cao S, Lin X. Role of microRNA-26b in glioma development and its mediated regulation on EphA2. PloS one. 2011; 6:e16264.

40. Coburn NG. Lymph nodes and gastric cancer. J Surg Oncol. 2009; 99:199-206.

41. Tie J, Pan Y, Zhao L, Wu K, Liu J, Sun S, Guo X, Wang B, Gang Y, Zhang Y, Li Q, Qiao T, Zhao Q, et al. MiR-218 inhibits invasion and metastasis of gastric cancer by targeting the Robo1 receptor. PLoS genetics. 2010; 6:e1000879.

42. Sun T, Wang C, Xing J, Wu D. miR-429 modulates the expression of c-myc in human gastric carcinoma cells. Eur J Cancer. 2011; 47:2552-2559.

43. Lo SS, Hung PS, Chen JH, Tu HF, Fang WL, Chen CY, Chen WT, Gong NR, Wu CW. Overexpression of miR370 and downregulation of its novel target TGFbeta-RII contribute to the progression of gastric carcinoma. Oncogene. 2012; 31:226-237. 
44. Kogo R, Mimori K, Tanaka F, Komune S, Mori M. Clinical significance of miR-146a in gastric cancer cases. Clin Cancer Res. 2011; 17:4277-4284.

45. Christiansen A, Dyrskjot L. The functional role of the novel biomarker karyopherin alpha 2 (KPNA2) in cancer. Cancer Lett. 2013; 331:18-23.

46. Li XL, Jia LL, Shi MM, Li X, Li ZH, Li HF, Wang EH, Jia XS. Downregulation of KPNA2 in non-small-cell lung cancer is associated with Oct4 expression. J Transl Med. 2013; 11:232.

47. Kim SY, Kang HT, Han JA, Park SC. The transcription factor $\mathrm{Sp} 1$ is responsible for aging-dependent altered nucleocytoplasmic trafficking. Aging cell. 2012; 11:1102-1109.

48. Wight TN, Kinsella MG, Qwarnstrom EE. The role of proteoglycans in cell adhesion, migration and proliferation. Curr Opin Cell Biol. 1992; 4:793-801.

49. Japanese Gastric Cancer A. Japanese Classification of Gastric Carcinoma - 2nd English Edition. Gastric Cancer. $1998 ; 1: 10-24$.
50. Chen C, Ridzon DA, Broomer AJ, Zhou Z, Lee DH, Nguyen JT, Barbisin M, Xu NL, Mahuvakar VR, Andersen MR, Lao KQ, Livak KJ, Guegler KJ. Real-time quantification of microRNAs by stem-loop RT-PCR. Nucleic Acids Res. 2005; 33:e179.

51. Shih $\mathrm{CH}$, Chen SL, Yen CC, Huang YH, Chen CD, Lee YS, Lin KH. Thyroid hormone receptor-dependent transcriptional regulation of fibrinogen and coagulation proteins. Endocrinology. 2004; 145:2804-2814.

52. Tsai MM, Lin PY, Cheng WL, Tsai CY, Chi HC, Chen CY, Tseng YH, Cheng YF, Chen CD, Liang Y, Liao CJ, Wu SM, Lin $\mathrm{YH}$, et al. Overexpression of ADP-ribosylation factor 1 in human gastric carcinoma and its clinicopathological significance. Cancer Sci. 2012; 103:1136-1144.

53. Repesh LA. A new in vitro assay for quantitating tumor cell invasion. Invasion Metastasis. 1989; 9:192-208. 